\title{
Intensive care management of severe traumatic brain injury in India
}

Traumatic brain injury (TBI) is a major public health problem in India. Lack of reliable and good quality national or regional data has thwarted its recognition. Considering this lacuna in the publication of experience with TBI, an article published in the current issue of Journal of Neuroscience in Rural Practice by Kamal et al. provides a good overview of the causative factors, injury profile, management details, and outcome of moderate and severe TBI after getting treated in Intensive Care Unit (ICU) of a level one trauma center in the capital of India. ${ }^{[1]}$ The authors report a large experience of severe and moderate TBI managed in ICU. Authors have evaluated a number of parameters in 1527 patients admitted in ICU of the trauma center over 26 months duration. However, the rational for combining severe and moderate TBI is not explained. The prognosis of severe TBI is considerably different from moderate TBI. ${ }^{[2]}$ The study could have been restricted to severe TBI as the number of moderate TBI cases were few in their study. However, authors should be congratulated for a detailed analysis of patient-related parameters such as demographics, physiological parameters, and radiological findings at admission and follow-up at 6 months. The authors also had a large number of patients (more than one-third patients with severe TBI) who underwent intracranial pressure monitoring, which is not routinely practiced in India even at large volume neurotrauma centers. The authors reported in hospital mortality of $38.56 \%$ and a 6 -month mortality of $64 \%$ among severe TBI. These figures are significantly higher than that reported for severe TBI from elsewhere, particularly the mortality at follow-up. This result should be taken with caution as the number of patients available for follow-up were only $70 \%$. In a similar study by Tripathi et al., the mortality at follow-up after 3 months was $32 \%{ }^{[3]}$ They had a follow-up rate of $88 \%$. However, they recruited all the consecutive patients whether they were admitted to ICU or not is not mentioned. A smaller but prospective study with good follow-up could give more information than a retrospective study with a large number of patients with poor follow-up. In recently published two prospective studies of critical care management of severe TBI from India, the follow-up rates were $99 \%$ and $89 \%$, respectively. The 6 months mortality reported in these studies were $33.5 \%$ and $30.4 \%$, respectively. ${ }^{[4.5]}$ Lack of follow-up is a serious concern in most of the Indian studies. Deepika et al. showed that the predictive validity of disability rating scale (DRS) at the time of discharge from acute care was good in determining functional outcome at 6 months. They proposed that DRS at discharge can be used as surrogate outcome assessment tool for the functional outcome when follow-up is not available. ${ }^{[5]}$ The other reason for high mortality in Kamal's study was more number $(25 \%)$ of patients with hypotension, and more numbers $(28 \%)$ with extracranial injuries. The study by Deepika et al. had patients with only isolated severe TBI, by Gupta et al., had fewer extracranial injuries, and Tripathi et al. did not mention about extracranial

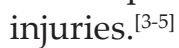

At best, the study by Kamal et al. provides a database of severe TBI managed in ICU, which can be used for comparison with other centers in India. It still does not provide reliable data on the outcome of severe TBI except for in-hospital mortality.

Manjul Tripathi, Dhaval Shukla ${ }^{1}$

Department of Neurosurgery, Postgraduate Institute of Medical Education and Research, Chandigarh, 'Department of Neurosurgery, National Institute of Mental Health and Neurosciences, Bengaluru, Karnataka, India

Address for correspondence: Dr. Dhaval Shukla,
National Institute of Mental Health and Neurosciences, Bengaluru - 560 029, Karnataka, India. E-mail: neurodhaval@rediffmail.com

\section{References}

1. Kamal VK, Agrawal D, Pandey RM. Epidemiology, clinical characteristics and outcomes of traumatic brain injury: Evidences from integrated level 1 trauma center in India. J Neurosci Rural Pract 2016;7:515-25.

2. Godoy DA, Rubiano A, Rabinstein AA, Bullock R, Sahuquillo J. Moderate traumatic brain injury: The grey zone of neurotrauma. Neurocrit Care 2016. [Epub ahead of print]. 
3. Tripathi M, Tewari MK, Mukherjee KK, Mathuriya SN. Profile of patients with head injury among vehicular accidents: An experience from a tertiary care centre of India. Neurol India 2014;62:610-7.

4. Gupta D, Sharma D, Kannan N, Prapruettham S, Mock C, Wang J, et al. Guideline adherence and outcomes in severe adult traumatic brain injury for the CHIRAG (Collaborative Head Injury and Guidelines) Study. World Neurosurg 2016;89:169-79.

5. Deepika A, Bhagavatula ID, Shukla D. Predictive validity of disability rating scale in determining functional outcome after severe traumatic brain injury. Neurol India 2016. [In press].

This is an open access article distributed under the terms of the Creative Commons Attribution-NonCommercial-ShareAlike 3.0 License, which allows others to remix, tweak, and build upon the work non-commercially, as long as the author is credited and the new creations are licensed under the identical terms.

\begin{tabular}{|l|l|}
\hline \multicolumn{2}{|c|}{ Access this article online } \\
\hline Quick Response Code: & Website: \\
\hline & www.ruralneuropractice.com \\
\cline { 2 - 2 } & \\
\hline
\end{tabular}

How to cite this article: Tripathi $M$, Shukla $D$. Intensive care management of severe traumatic brain injury in India. J Neurosci Rural Pract 2016;7:481-2. 